\title{
Phenolic Content, Antioxidant Capacity and Quality of Chokeberry (Aronia melanocarpa) Products
}

\author{
Mandica-Tamara Tolić ${ }^{*}$, Irena Landeka Jurčević ${ }^{2}$ Ines Panjkota Krbavčić2, \\ Ksenija Marković ${ }^{2}$ and Nada Vahčić ${ }^{2}$ \\ ${ }^{1}$ Clinical Hospital Dubrava, Avenija Gojka Šuška 6, HR-10000 Zagreb, Croatia
}

${ }^{2}$ Faculty of Food Technology and Biotechnology, University of Zagreb, Pierottijeva 6,

HR-10000 Zagreb, Croatia

Received: July 26, 2014

Accepted: February 19, 2015

\begin{abstract}
Summary
Chokeberries (Aronia melanocarpa) are rarely used in diet in Croatia but they have high content of polyphenolic compounds and one of the highest in vitro antioxidant activities among fruits. The aim of this study is to compare the quality, phenolic content and antioxidant capacity of different chokeberry products (juices, powders, fruit tea, capsules and dried berries). It can be expected that processing influences antioxidant activity and phenolic content of final products reaching consumers. Characterisation of phenolic compounds was carried out by using spectroscopic methods (Folin-Ciocalteu and $\mathrm{pH}$ differential methods). Antioxidant activity of chokeberry products was determined using 2,2-diphenyl-2picrylhydrazyl (DPPH) and ferric reducing antioxidant power (FRAP) methods. The results show that the investigated products contain high amount of phenols (3002 to $6639 \mathrm{mg}$ per L and 1494 to $5292 \mathrm{mg}$ per $100 \mathrm{~g}$ of dry matter) and lower amount of total anthocyanins (150 to $1228 \mathrm{mg}$ per $\mathrm{L}$ and $141 \mathrm{to} 2468 \mathrm{mg}$ per $100 \mathrm{~g}$ of dry matter). The examined juices and other chokeberry products possess high antioxidant capacity (12.09 to $40.19 \mathrm{mmol}$ per L or 58.49 to $191.31 \mathrm{mmol}$ per $100 \mathrm{~g}$ of dry matter, respectively) and reducing power (38.71 to $79.86 \mathrm{mmol}$ per L or 13.50 to $68.60 \mathrm{mmol}$ per $100 \mathrm{~g}$ of dry matter, respectively). On the basis of phenolic content and antioxidant activity, capsules and powders stand out among other products. The study indicates that there are significant differences $(\mathrm{p}<0.05)$ in the quality, phenolic content and antioxidant capacity among examined products.
\end{abstract}

Key words: chokeberry products, quality, phenols, anthocyanins, DPPH, FRAP

\section{Introduction}

Increased consumption of fruits and vegetables is recommended in dietary guidelines worldwide (1). Among different fruit species, berries have attracted great attention for their bioactivity. In addition to nutritive dietary components (vitamins, minerals, sugars, organic acids, dietary fibres and unsaturated fats), berries are also a good source of different classes of phytochemicals such as flavonoids (anthocyanins, flavonols and flavanols), tannins (proanthocyanidins, ellagitannins and gallotannins), stilbenoids (e.g. resveratrol), phenolic acids (hydroxyben- zoic and hydroxycinnamic acid derivates) and lignans (2). Berry fruits are popularly consumed not only in fresh and frozen forms but also as processed and derived products including canned fruits, yogurts, beverages, jams and jellies. In addition, there has been a growing trend in the intake of berry extracts as ingredients in functional foods and dietary supplements, which may or may not be combined with other colourful fruits, vegetables and herbal extracts $(1,2)$. In Croatia, berries like red raspberries, blackberries, blueberries and strawberries are commonly used in diet, but black chokeberry is almost unknown fruit (3). 
Black chokeberry (Aronia melanocarpa (Michx.) Elliott) belongs to the Rosaceae family, subfamily Maloideae, and is a deciduous shrub originating from the eastern part of North America $(4,5)$ where it has been used for the treatment of cold by native Americans (Abnakians and Potawatomians). Today, chokeberry is also cultivated in Eastern European countries and Russia (6), where it is used for production of homemade or commercial juices, jams, fruit tea, wine and natural food colourants $(5,7)$. It shows high resistance to frost, mechanized harvesting, damage during transportation and cold storage. Due to these advantages, popularity of chokeberry has increased recently (8). Chokeberries have very high contents of polyphenols, namely phenolic acids, proanthocyanidins, anthocyanins, flavonols and flavanones (9-12). In a study where 143 different plant samples were analysed for polyphenols, the highest contents of these compounds were found in chokeberry (13). The high content and composition of the phenolic constituents of Aronia melanocarpa seem to be responsible for the wide range of the fruit's potential medicinal and therapeutic effects. Chokeberries have one of the highest in vitro antioxidant activities among fruits. The mechanisms of the in vivo antioxidant activity of their phenolics after absorption spread out far beyond radical scavenging and include suppressing the formation of reactive oxygen species (ROS) and reactive nitrogen species (RNS), inhibition of prooxidant, and restoration of antioxidant enzymes, and probably also cellular signalling to regulate the level of antioxidant compounds and enzymes (14). Although recent studies have pointed out different positive effects of chokeberry juices and extracts (15-21), current evidence of effectiveness does not yet meet the accepted standards that would secure chokeberry products an indisputable place in therapy. Promising indications from laboratory and clinical data need to be confirmed in more rigorous studies before putative therapeutic uses can be confidently recommended for chokeberry products (22).

There are no studies on compositional and physical properties of Aronia melanocarpa products present on the Croatian market. Therefore, in this study 22 chokeberry products are evaluated. The objective of this study is to evaluate the physicochemical properties, the content of phenolics (total phenolics, flavonoids, nonflavonoids and anthocyanins) as well as antioxidant properties of different chokeberry products present on the market.

\section{Materials and Methods}

Chokeberry products (Table 1) were purchased on Croatian markets during February 2014. There was only one requirement: they had to contain only chokeberry, without added sugar or other fruits. Products were stored at $4{ }^{\circ} \mathrm{C}$ until analysis.

\section{Determination of physicochemical parameters}

Total solid content of the chokeberry products was determined using a gravimetric method. A mass of $(2 \pm$ $0.0001) \mathrm{g}$ of chokeberry sample was mixed with about $5 \mathrm{~g}$ of sea sand and dried at $105{ }^{\circ} \mathrm{C}$ until constant mass. Solu- ble solid content was determined with a digital refractometer (Atago PAL-3, Tokyo, Japan) and expressed as ${ }^{\circ}$ Brix. Sample $\mathrm{pH}$ was determined at room temperature using an MA $5740 \mathrm{pH}$ meter (ISKRA, Kranj, Slovenia). Two-point calibration was obtained using buffers at $\mathrm{pH}=7.0$ and 4.0. Titratable acidity was determined by titration of the water solution of chokeberry product with $0.1 \mathrm{M} \mathrm{NaOH}$ to end point of neutral $\mathrm{pH}(8.1)$. The volume of $0.1 \mathrm{M} \mathrm{NaOH}$ required to reach $\mathrm{pH}=8.1 \pm 0.2$ was determined. The total titratable acidity was expressed as percentage of citric acid using a conversion factor of 0.070 (23).

Table 1. Producer, country of origin, fruit content and composition of chokeberry products

\begin{tabular}{|c|c|c|c|}
\hline Producer & $\begin{array}{l}\text { Country } \\
\text { of origin }\end{array}$ & $\frac{w \text { (fruit) }}{\%}$ & Composition \\
\hline \multicolumn{4}{|c|}{ Juices } \\
\hline $\begin{array}{l}\text { Aronia Original } \\
\text { Naturprodukte } \mathrm{GmbH}\end{array}$ & Germany & 100 & Chokeberry fruit \\
\hline Aronija Live d.o.o. & Croatia & 100 & Chokeberry fruit \\
\hline Vitanea LTD & Bulgaria & 100 & Chokeberry fruit \\
\hline Alnavit $\mathrm{GmbH}$ & Germany & 100 & Chokeberry fruit \\
\hline Biotta AG & Germany & 100 & Chokeberry fruit \\
\hline NA & Poland & 100 & Chokeberry fruit \\
\hline Bobica d.o.o. & Croatia & 100 & Chokeberry fruit \\
\hline Armedina d.o.o. & Serbia & 100 & Chokeberry fruit \\
\hline Aronija Vita d.o.o. & Serbia & 100 & Chokeberry fruit \\
\hline Voelkel GmbH & Germany & 100 & Chokeberry fruit \\
\hline $\begin{array}{l}\text { Medicura } \\
\text { Naturprodukte AG }\end{array}$ & Germany & 100 & Chokeberry fruit \\
\hline \multicolumn{4}{|c|}{ Powders } \\
\hline $\begin{array}{l}\text { Aronia Original } \\
\text { Naturprodukte } \mathrm{GmbH}\end{array}$ & Germany & 100 & Chokeberry pulp \\
\hline Bobica d.o.o. & Croatia & 100 & Chokeberry fruit \\
\hline Aronija Vita d.o.o. & Serbia & 100 & Chokeberry pomace \\
\hline \multicolumn{4}{|c|}{ Capsules } \\
\hline Darvitalis d.o.o. & Serbia & 100 & Chokeberry extract \\
\hline Bobica d.o.o. & Croatia & 100 & Chokeberry extract \\
\hline \multicolumn{4}{|c|}{ Fruit tea* } \\
\hline Aronija Live d.o.o. & Croatia & 100 & Chokeberry pomace \\
\hline Darvitalis d.o.o. & Serbia & 100 & Chokeberry pomace \\
\hline Bobica d.o.o. & Croatia & 93 & $\begin{array}{l}\text { Chokeberry pomace; } \\
\text { chokeberry leaves }\end{array}$ \\
\hline Vitanea LTD & Bulgaria & 100 & Chokeberry pomace \\
\hline \multicolumn{4}{|c|}{ Dried berries } \\
\hline $\begin{array}{l}\text { Aronia Original } \\
\text { Naturprodukte } \mathrm{GmbH}\end{array}$ & Germany & 100 & Chokeberry fruit \\
\hline Bobica d.o.o. & Croatia & 100 & Chokeberry fruit \\
\hline
\end{tabular}

*Dried and ground chokeberry pomace. The pomace consists of chokeberry skin and pips that are left when chokeberries are processed to become chokeberry juice

NA=data about producer not available, imported by Biovega d.o.o. 


\section{Determination of juice colour}

The colour of the chokeberry juices was measured in a transmitted mode through Konica Minolta CM-3500d spectrophotometer (Konica Minolta, Inc., Tokyo, Japan). Measurements were conducted in CIE $L^{*} a^{*} b^{*}$ system. $L^{*}$ is a measure of lightness, where values range from completely opaque (0) to completely transparent (100), $a^{*}$ is a measure of redness (or $-a^{*}$ of greenness) and $b^{*}$ of yellowness (or $-b^{*}$ of blueness) on the hue circle. The hue angle, $h^{\circ}$, (Eq. 1) describes the relative amounts of redness and yellowness where $0^{\circ} / 360^{\circ}$ is defined for red/magenta, $90^{\circ}$ for yellow, $180^{\circ}$ for green and $270^{\circ}$ for blue colour:

$$
h^{\circ}=\arctan \frac{b^{*}}{a^{*}}
$$

Chroma $\left(C^{*}\right)$ gives further information on the saturation or intensity of colour $(24,25)$ :

$$
C^{*}=\sqrt{a^{2}+b^{2}}
$$

\section{Extraction of phenolics}

Phenolics were extracted according to the modified method by Benvenuti et al. (26). Exactly $6 \mathrm{~g}$ of samples were weighed out and mixed with $20 \mathrm{~mL}$ of methanol/2 \% $\mathrm{HCl}$ (95:5, by volume). After $60 \mathrm{~min}$ the solution was filtered under vacuum in a 50-mL volumetric flask. Extraction of the residue was repeated using the same conditions. The filtrates were combined and adjusted to $50 \mathrm{~mL}$ in a volumetric flask with methanol/2 $\% \mathrm{HCl}$ (95:5, by volume). The obtained extract was used for determination of total phenolic content (TPC), total nonflavonoids (TN), total anthocyanins (TA) as well as for antioxidant capacity assay by DPPH method and reducing power assay using FRAP method.

\section{Determination of total phenolics}

For determination of TPC, a method with Folin-Ciocalteu reagent was used (27). An aliquot $(20 \mu \mathrm{L})$ of diluted chokeberry extract or standard solutions of gallic acid $(25-500 \mathrm{mg} / \mathrm{L})$ was mixed with $1580 \mu \mathrm{L}$ of distilled water and $100 \mu \mathrm{L}$ of Folin-Ciocalteu reagent. A volume of 300 $\mu \mathrm{L}$ of sodium carbonate solution $(200 \mathrm{~g} / \mathrm{L})$ was added to the mixture which was then shaken. After incubation at room temperature for $2 \mathrm{~h}$, the resulting absorbance was measured by the spectrophotometer Pye Unicam SP6-500 (Pye Ltd., Philips, Cambridge, UK) at the wavelength of $765 \mathrm{~nm}$ against the blank sample, which was used as reference. The results were calculated according to the calibration curve for gallic acid as follows:

$$
y=0.00103 x-0.01128
$$

where $\mathrm{y}$ is the absorbance at $765 \mathrm{~nm}$ and $\mathrm{x}$ is the concentration of gallic acid in $\mathrm{mg} / \mathrm{L} ; \mathrm{R}^{2}=0.9973$. Total phenolics were expressed as $\mathrm{mg}$ of gallic acid equivalents (GAE) per $\mathrm{L}$ of chokeberry juices and as mg of GAE per $100 \mathrm{~g}$ of dry matter $(\mathrm{dm})$ of other chokeberry products.

\section{Determination of total flavonoid and nonflavonoid contents}

Determination of total flavonoid (TF) content was performed by the indirect method using formaldehyde to precipitate these compounds, as described by Ough and Amerine (28). A mixture of $3 \mathrm{~mL}$ of chokeberry extract solution, $1.5 \mathrm{~mL}$ of aqueous solution of hydrochloric acid (1:4, by volume) and $3 \mathrm{~mL}$ of formaldehyde was prepared in a 25 -mL flask. In order to remove air, nitrogen gas was injected and the stoppered flask was left in the dark for 24 $\mathrm{h}$ at $22^{\circ} \mathrm{C}$. The next day it was filtered and the clear liquid was used in the same procedure (27) as the one used to prepare samples for TPC determination. The amount of TF was calculated as the difference between total phenolics and total nonflavonoids (TN). The results were expressed as mg of GAE per $L$ and as mg of GAE per $100 \mathrm{~g}$ of $\mathrm{dm}$ for chokeberry juices and other products, respectively.

\section{Determination of total anthocyanins}

Total anthocyanin (TA) content, calculated as cyanidin-3-glucoside, was determined by the $\mathrm{pH}$ differential method of Giusti and Wrolstad (29). Two dilutions of each chokeberry extract were prepared, one with potassium chloride buffer $(\mathrm{pH}=1.0)$, and the other with sodium acetate buffer $(\mathrm{pH}=4.5)$. After $15 \mathrm{~min}$ of incubation at room temperature, the absorbance was measured simultaneously at the wavelengths of 510 and $700 \mathrm{~nm}$. The content of TA was calculated using Eqs. 4 and 5 with molar absorption coefficient of cyanidin-3-glucoside of $26900 \mathrm{~L} /$ $(\mathrm{mol} \cdot \mathrm{cm})$ and molar mass of $449.2 \mathrm{~g} / \mathrm{mol}$ :

$$
\begin{gathered}
A=\left(A_{510 \mathrm{~nm}}-A_{700 \mathrm{~nm}}\right)_{\mathrm{pH}=1.0}-\left(A_{510 \mathrm{~nm}}-A_{700 \mathrm{~nm}}\right)_{\mathrm{pH}=4.5} \\
\mathrm{TA}=\frac{A}{\varepsilon \cdot L} \cdot M_{\mathrm{r}} \cdot \mathrm{DF} \cdot \frac{V}{m} \cdot 100
\end{gathered}
$$

where $A$ is absorbance, $\varepsilon$ is molar absorption coefficient of cyanidin-3-glucoside equivalents (CGE) $(\mathrm{L} /(\mathrm{mol} \cdot \mathrm{cm})), L$ is cell pathlength $(1 \mathrm{~cm}), M_{\mathrm{r}}$ is molecular mass of CGE, DF is dilution factor, $V$ is final volume $(\mathrm{mL})$, and $m$ is mass of the sample (mg). Results were expressed as mg of CGE per $\mathrm{L}$ of chokeberry juices and as mg of CGE per $100 \mathrm{~g}$ of $\mathrm{dm}$ of other products.

\section{Determination of total antioxidant capacity by DPPH method}

The effect of chokeberry products on 2,2-diphenyl-2picrylhydrazyl (DPPH) radical was determined according to the method of Brand-Williams et al. (30). The method was based on the reduction of stable DPPH radical in the presence of antioxidants. A volume of $2 \mathrm{~mL}$ of diluted chokeberry extract or methanol solution of Trolox (25-200 $\mu \mathrm{mol} / \mathrm{L}$ ) was mixed with $2 \mathrm{~mL}$ of methanol and $1 \mathrm{~mL}$ of $0.5 \mathrm{mM}$ DPPH methanolic solution. The mixture was vortexed and kept in the dark for $20 \mathrm{~min}$. After incubation, the absorbance was measured at the wavelength of 517 $\mathrm{nm}$ against a blank of methanol without DPPH. The results were calculated according to the calibration curve for Trolox:

$$
y=-0.62525 x+1.33117
$$

where $\mathrm{y}$ is the absorbance at $517 \mathrm{~nm}$ and $\mathrm{x}$ is the concentration of Trolox in $\mu \mathrm{mol} / \mathrm{L} ; \mathrm{R}^{2}=0.9817$. DPPH values were expressed as mmol of Trolox equivalents (TE) per L and mmol of TE per $100 \mathrm{~g}$ of $\mathrm{dm}$ for chokeberry juices and other products, respectively. 


\section{Determination of FRAP}

The ferric reducing antioxidant power (FRAP) assay was conducted according to Benzie and Strain (31). The method is based on the reduction of the $\mathrm{Fe}^{3+}-2,4,6$-tripyridyl-s-triazine (TPTZ) complex to the ferrous form at low $\mathrm{pH}$. This reduction is monitored by measuring the absorbance change at $595 \mathrm{~nm}$. The FRAP reagent was prepared from $5 \mathrm{~mL}$ of TPTZ solution $(10 \mathrm{mmol} / \mathrm{L})$ in hydrochloric acid $(40 \mathrm{mmol} / \mathrm{L})$ and $5 \mathrm{~mL}$ of $\mathrm{FeCl}_{3}$ solution $(20$ $\mathrm{mmol} / \mathrm{L})$ mixed with $50 \mathrm{~mL}$ of acetate buffer $(0.3 \mathrm{~mol} / \mathrm{L}$, $\mathrm{pH}=3.6)$. For the determination of the antioxidant capacity, the FRAP reagent $(2.08 \mathrm{~mL})$ was mixed with $240 \mu \mathrm{L}$ of water and $80 \mu \mathrm{L}$ of the appropriately diluted sample or standard solution of $\mathrm{FeSO}_{4} \cdot 7 \mathrm{H}_{2} \mathrm{O}(0.125-2.000 \mathrm{mmol} / \mathrm{L})$. The mixture was allowed to stand for $5 \mathrm{~min}$ at $37^{\circ} \mathrm{C}$ before the absorbance was measured at $595 \mathrm{~nm}$. FRAP values were calculated according to the calibration curve for $\mathrm{FeSO}_{4} \cdot 7 \mathrm{H}_{2} \mathrm{O}$ :

$$
\mathrm{y}=0.72126 \mathrm{x}-0.06396
$$

where $\mathrm{y}$ is the absorbance at $595 \mathrm{~nm}$ and $\mathrm{x}$ is the concentration of $\mathrm{FeSO}_{4} \cdot 7 \mathrm{H}_{2} \mathrm{O}$ in $\mathrm{mmol} / \mathrm{L} ; \mathrm{R}^{2}=0.9987$, and they were expressed as mmol of $\mathrm{Fe}^{2+}$ equivalents $(\mathrm{FE})$ per $\mathrm{L}$ and as mmol of FE per $100 \mathrm{~g}$ of $\mathrm{dm}$ for chokeberry juices and other products, respectively.

\section{Statistical analysis}

The data were analysed using STATISTICA v. 12.0 (Statsoft Inc, Tulsa, OK, USA). Analysis of variance (ANOVA) was used to establish significant differences between and within groups of chokeberry products. Differences were considered significant at $p \leq 0.05$. Values were expressed as means $(N=3)$. For comparison of the contents of TPC, TF, TN, TA and DPPH or FRAP assays and also for comparison of colour parameters and TPC, TF, TN or TA contents, the coefficients of correlation were determined for each combination.

\section{Results and Discussion}

Chokeberry fruits are not popular as table fruits but they are generally consumed as processed chokeberry products including juice, jam, syrup and nutritional supplements. Data on the phenolic contents of chokeberry have been reported in several studies $(3,6,26,32-35)$, and the present study contributes to the existing knowledge by providing new data on different chokeberry products such as powders, capsules, fruit tea and dried berries.

\section{Physicochemical parameters and juice colour}

The analysis of chokeberry samples indicated different physicochemical properties among groups of products as well within groups (Table 2). In case of chokeberry juices, the total solid content ranged from $13.42 \%$ in juice sample J10 to $21.54 \%$ in juice sample J2, while in the other samples it was much higher. Chokeberry capsules had the highest total solid content among groups (mean value $93.78 \%$ ) followed by chokeberry powders (mean value $92.35 \%$ ), fruit tea (mean value $91.49 \%$ ) and dried berries (mean value $83.31 \%$ ). In research of Mayer-Miebach et al.
Table 2. Physicochemical properties of chokeberry products

\begin{tabular}{|c|c|c|c|c|c|}
\hline Sample & $\mathrm{pH}$ & TTA $/ \%$ & $\begin{array}{l}\text { Total solid } \\
\text { content } / \%\end{array}$ & ${ }^{\circ}$ Brix & $\begin{array}{l}{ }^{\circ} \text { Brix } \\
\text { TTA }\end{array}$ \\
\hline \multicolumn{6}{|c|}{ Juices } \\
\hline $\mathrm{J} 1$ & $3.90 \pm 0.02$ & $0.67 \pm 0.07$ & $14.70 \pm 0.04$ & 14.56 & 24.72 \\
\hline $\mathrm{J} 2$ & $3.90 \pm 0.02$ & $0.29 \pm 0.07$ & $21.54 \pm 0.03$ & 20.99 & 78.54 \\
\hline $\mathrm{J} 3$ & $3.86 \pm 0.02$ & $0.85 \pm 0.07$ & $18.98 \pm 0.14$ & 18.52 & 23.98 \\
\hline $\mathrm{J} 4$ & $3.71 \pm 0.03$ & $1.13 \pm 0.12$ & $15.75 \pm 0.11$ & 15.47 & 15.20 \\
\hline $\mathrm{J} 5$ & $3.80 \pm 0.03$ & $1.06 \pm 0.07$ & $15.79 \pm 0.15$ & 15.27 & 16.08 \\
\hline J6 & $3.68 \pm 0.02$ & $1.26 \pm 0.07$ & $14.50 \pm 0.16$ & 14.09 & 12.52 \\
\hline $\mathrm{J} 7$ & $3.74 \pm 0.02$ & $0.87 \pm 0.07$ & $14.61 \pm 0.22$ & 13.99 & 18.06 \\
\hline J8 & $3.75 \pm 0.02$ & $1.32 \pm 0.07$ & $17.01 \pm 0.21$ & 17.34 & 14.61 \\
\hline J9 & $3.92 \pm 0.01$ & $0.84 \pm 0.07$ & $14.32 \pm 0.11$ & 13.69 & 18.28 \\
\hline $\mathrm{J} 10$ & $3.54 \pm 0.01$ & $1.30 \pm 0.07$ & $13.42 \pm 0.05$ & 13.30 & 11.48 \\
\hline $\mathrm{J} 11$ & $3.89 \pm 0.02$ & $0.97 \pm 0.07$ & $14.27 \pm 0.01$ & 13.79 & 16.01 \\
\hline \multicolumn{6}{|c|}{ Powders } \\
\hline P1 & $4.10 \pm 0.02$ & $1.67 \pm 0.07$ & $94.797 \pm 0.001$ & 26.75 & 16.02 \\
\hline P2 & $4.02 \pm 0.01$ & $2.30 \pm 0.07$ & $91.82 \pm 0.32$ & 37.53 & 16.36 \\
\hline P3 & $4.13 \pm 0.01$ & $2.17 \pm 0.07$ & $90.44 \pm 0.15$ & 37.34 & 17.24 \\
\hline \multicolumn{6}{|c|}{ Capsules } \\
\hline $\mathrm{C} 1$ & $3.31 \pm 0.02$ & $4.66 \pm 0.07$ & $93.96 \pm 0.27$ & 83.71 & 17.97 \\
\hline $\mathrm{C} 2$ & $4.10 \pm 0.01$ & $2.10 \pm 0.07$ & $93.60 \pm 0.26$ & 31.91 & 15.23 \\
\hline \multicolumn{6}{|c|}{ Fruit tea } \\
\hline FT1 & $4.13 \pm 0.02$ & $1.34 \pm 0.06$ & $91.90 \pm 0.26$ & 38.22 & 28.52 \\
\hline FT2 & $4.01 \pm 0.01$ & $1.08 \pm 0.06$ & $88.32 \pm 0.27$ & 12.17 & 11.24 \\
\hline FT3 & $4.01 \pm 0.02$ & $1.60 \pm 0.07$ & $89.74 \pm 0.19$ & 33.42 & 20.86 \\
\hline FT4 & $4.04 \pm 0.02$ & $1.37 \pm 0.06$ & $96.01 \pm 0.14$ & 25.48 & 18.63 \\
\hline \multicolumn{6}{|c|}{ Dried berries } \\
\hline DB1 & $4.28 \pm 0.02$ & $(1.13 \pm 0.06)^{a}$ & $(84.61 \pm 0.92)^{b}$ & 25.49 & 22.62 \\
\hline DB2 & $4.01 \pm 0.02$ & $(1.37 \pm 0.11)^{\mathrm{a}}$ & $(82.00 \pm 0.55)^{\mathrm{b}}$ & 20.93 & 15.30 \\
\hline
\end{tabular}

The values are presented as mean \pm standard deviation (S.D.). The same letter in the superscript in the same column indicates no significant differences $(\mathrm{p}>0.05)$. TTA=total titratable acidity as citric acid, J1-J11=chokeberry juices, $\mathrm{P} 1-\mathrm{P} 3=$ chokeberry powder, $\mathrm{C}=$ chokeberry capsules, $\mathrm{FT}=$ chokeberry fruit tea, $\mathrm{DB}=$ chokeberry dried berries

(36) the dry matter content of berries ranged from 17.9 to $26.0 \%$, in juices from 11.1 to $17.4 \%$ and in pomace from 44.6 to $50 \%$. The mean value of total solid content of chokeberry capsules $(93.78 \%)$, fruit tea $(2.35 \%)$ and powders $(91.49 \%)$ present on the market is very similar to the results of Sójka et al. (37), who investigated chokeberry pomace obtained in an industrial-scale processing of fruit into juice. The lowest value of soluble solid content (13.70 ${ }^{\circ}$ Brix) was in juice sample J10, while the highest value characterised capsules, i.e. sample C1 (83.71 ${ }^{\circ}$ Brix). The soluble solid content in chokeberries depends on numerous factors: weather, environmental conditions, crop period and variety, and it amounts to 12.4 or $18.3 \%$ (5). Chokeberry products had a mean $\mathrm{pH}$ value of 3.90 ranging from 3.54 (sample J10) to 4.28 (sample DB1). The mean total titratable acidity (TTA) of all products was 1.42 (as percentage of citric acid) ranging from 0.29 (sample J2) to 
$4.66 \%$ (sample C1). Comparing the groups of products, it is evident that capsules have the highest total titratable acidity and juices the lowest. Ochmian et al. (5) reported similar values for titratable acidity in the range from 0.75 to $1.05 \mathrm{~g}$ of citric acid per $100 \mathrm{~g}$ of berries. The ${ }^{\circ} \mathrm{Brix} / \mathrm{TTA}$ ratio is a quality attribute used by the fruit industry to indicate the tartness of fruits and fruit juices (38). This ratio increases with maturity of the fruit and is used to identify the optimum maturity for harvesting to produce maximum product quality (39). The mean ${ }^{\circ} \mathrm{Brix} / \mathrm{TTA}$ ratio was 20.42 and ranged from 11.24 in the fruit tea sample FT2 to 78.54 in the juice sample J2 (Table 2). ANOVA showed significant differences of physicochemical properties among juices, powders, fruit tea, capsules and dried berries and also among individual samples within groups, with the exception of total solid content and total titratable acidity of samples of dried berries.

Since the colour of the product, especially juices, is extremely important feature that contributes to the overall quality, one of the aims of this paper was to determine colour parameters of chokeberry juices (Table 3 ). Values of variable $L^{*}$ were low in all samples, from 0.52 (juice sample J10) to 15.00 (juice sample J7), which indicates that samples were very dark since the variable $L^{*}$ varies from 0 representing black to 100 representing white. Similar values of the parameter $L^{*}$ of chokeberry juices were observed by Ochmian et al. (5). The $a^{*}$ value, providing information of the position in the colour gamut between green and red, measured on the juice surface ranged from 3.74 (juice sample J10) to 46.42 (juice sample J7). The juice surface colour defined by the $b^{*}$ parameter, indicating the location on the axis between yellow and blue colours, ranged from 0.88 (juice sample J10) to 25.84 (juice sample J7), which means that yellow colour is present. Positive $a^{*}$ values were also observed in chokeberry juices, pulp and fruit by Ochmian et al. (5) and in chokeberry powders by Horszwald et al. (40). In a research of Horszwald et al. (40) yellow colour was present in chokeberry powders, while in the work of Ochmian et al. (5) $b^{*}$ values were negative, which indicates the presence of blue colour. Parameters $L^{*}, C^{*}$ and $h^{\circ}$ are related to the physiological attributes of visual response (41). Hue describes the visible colour and chroma describes the brightness or intensity of the hue. Indices of $L^{*}, C^{*}$ and $h^{\circ}$ are usually useful for tracking colour changes (42). The decrease in chroma means an increase in the tonality of the fruit colour (43).

Table 4 shows the correlation coefficients between the colour parameters and TPC, TN, TF and TA, from which a negative correlation of colour parameters with the content of total nonflavonoids and of colour parameters with the content of total anthocyanins is evident.
Table 4. Correlation coefficients $(\mathrm{R})$ between phenolics and colour parameters of chokeberry juices

\begin{tabular}{ccccc}
\hline $\begin{array}{c}\text { Colour } \\
\text { parameters }\end{array}$ & TPC & TN & TF & TA \\
\hline$L^{*}$ & -0.21 & $-0.61^{\mathrm{a}}$ & -0.10 & $-0.76^{\mathrm{b}}$ \\
$a^{*}$ & -0.02 & $-0.52^{\mathrm{a}}$ & -0.08 & $-0.81^{\mathrm{b}}$ \\
$b^{*}$ & -0.21 & $-0.61^{\mathrm{a}}$ & -0.10 & $-0.76^{\mathrm{b}}$ \\
$h^{\circ}$ & $-0.28^{\mathrm{a}}$ & $-0.59^{\mathrm{a}}$ & -0.17 & $-0.70^{\mathrm{b}}$ \\
$C^{*}$ & -0.06 & $-0.54^{\mathrm{a}}$ & -0.04 & $-0.81^{\mathrm{b}}$ \\
\hline
\end{tabular}

${ }^{a, b}$ significant at $\mathrm{p} \leq 0.05$ and $\mathrm{p} \leq 0.001$, respectively

Contents of total phenolics (TPC), total nonflavonoids (TN), total flavonoids (TF) and total anthocyanins (TA) are expressed as mg per L. TPC, TN and TF are expressed as $\mathrm{mg}$ of gallic acid equivalents (GAE), while TA is expressed as mg of cyanidin-3-glucoside equivalents (CGE)

\section{Total phenolics, flavonoids, nonflavonoids and anthocyanins}

The content of total phenolics (TPC), total flavonoids (TF) and total nonflavonoids (TN) in twenty-two chokeberry products is given in Table 5. TPC ranged from 1494 $\mathrm{mg}$ of GAE per $100 \mathrm{~g}$ of $\mathrm{dm}$ in fruit tea sample FT3 to 5292 $\mathrm{mg}$ of GAE per $100 \mathrm{~g}$ of $\mathrm{dm}$ in capsule sample C2. Comparing the results of our research with the results of other authors, the mass fraction of TPC in chokeberry juices was lower than in the findings of others $(3,14,35,43)$. Some authors noticed higher values of phenolics in black chokeberry fruit in comparison with our results $(14,26,32-34)$, while Jurgoński et al. (44) reported much higher values of total phenolics in commercial chokeberry extract. Different cultivars of chokeberries were analysed and total phenolic values ranged from 8563.8 to $12055.7 \mathrm{mg}$ of GAE per $\mathrm{kg}$ of fresh mass (fm) (34). Lower or higher values reported in the literature might have resulted from different extraction methods used for analysis, differences in analytical procedures applied, different processing technologies and storage conditions, or differences in chokeberry cultivars (14). It was demonstrated that the total phenolics in hot-air-dried tomatoes increased up to $29 \%$ compared to the corresponding levels in fresh tomatoes (45). In comparison with other products, chokeberry juices had lower phenolic content, which might be related to the differences in their moisture content (46). In total phenolic content, flavonoids were predominant, and their amounts varied from $867 \mathrm{mg}$ of GAE per $100 \mathrm{~g}$ of $\mathrm{dm}$ in DB1 sample to $3317 \mathrm{mg}$ of GAE per $100 \mathrm{~g}$ of $\mathrm{dm}$ in P2 sample. Average total flavonoid content in chokeberry juices was $3180 \mathrm{mg}$ of GAE per L. It was calculated that percentages of TF in

Table 3. Colour parameters of chokeberry juice samples (J1-J11)

\begin{tabular}{|c|c|c|c|c|c|c|c|c|c|c|c|}
\hline \multirow{2}{*}{$\begin{array}{c}\text { Colour } \\
\text { parameters }\end{array}$} & \multicolumn{11}{|c|}{ Sample } \\
\hline & $\mathrm{J} 1$ & $\mathrm{~J} 2$ & J3 & $\mathrm{J} 4$ & $\mathrm{~J} 5$ & $\mathrm{~J} 6$ & $\mathrm{~J} 7$ & $\mathrm{~J} 8$ & J9 & $\mathrm{J} 10$ & J11 \\
\hline$L^{*}$ & 1.20 & 5.93 & 8.87 & 4.27 & 13.85 & 2.38 & 15.00 & 5.91 & 9.75 & 0.52 & 5.31 \\
\hline$a^{*}$ & 8.14 & 33.95 & 39.29 & 27.76 & 44.92 & 16.64 & 46.42 & 33.51 & 39.44 & 3.74 & 31.58 \\
\hline$b^{*}$ & 2.04 & 10.19 & 15.21 & 7.35 & 23.79 & 4.08 & 25.84 & 10.15 & 16.79 & 0.88 & 9.12 \\
\hline$h^{\circ}$ & 14.1 & 16.7 & 21.2 & 14.8 & 27.9 & 13.8 & 29.1 & 16.9 & 23.1 & 13.2 & 16.1 \\
\hline$C^{*}$ & 8.4 & 35.4 & 42.1 & 28.7 & 50.8 & 17.1 & 53.1 & 35.0 & 42.9 & 3.8 & 32.9 \\
\hline
\end{tabular}


Table 5. Total phenolics (TPC), total nonflavonoids (TN), total flavonoids (TF) and total anthocyanins (TA) in chokeberry products

\begin{tabular}{|c|c|c|c|c|}
\hline Sample & TPC & $\mathrm{TN}$ & $\mathrm{TF}$ & TA \\
\hline \multicolumn{5}{|c|}{ Juices } \\
\hline $\mathrm{J} 1$ & $5202 \pm 252$ & $1383 \pm 124$ & $3819 \pm 160$ & $526 \pm 20$ \\
\hline $\mathrm{J} 2$ & $5448 \pm 479$ & $1064 \pm 92$ & $4384 \pm 571$ & $592 \pm 24$ \\
\hline $\mathrm{J} 3$ & $3908 \pm 682$ & $1088 \pm 240$ & $2819 \pm 451$ & $216 \pm 10$ \\
\hline $\mathrm{J} 4$ & $3358 \pm 702$ & $1090 \pm 161$ & $2267 \pm 550$ & $434 \pm 13$ \\
\hline $\mathrm{J} 5$ & $4672 \pm 644$ & $1156 \pm 259$ & $3515 \pm 384$ & $154 \pm 6$ \\
\hline $\mathrm{J} 6$ & $4083 \pm 490$ & $1415 \pm 174$ & $2667 \pm 330$ & $504 \pm 16$ \\
\hline $\mathrm{J} 7$ & $3002 \pm 388$ & $808 \pm 52$ & $2193 \pm 386$ & $150 \pm 4$ \\
\hline $\mathrm{J} 8$ & $6639 \pm 455$ & $1368 \pm 83$ & $5271 \pm 527$ & $541 \pm 29$ \\
\hline J9 & $3759 \pm 692$ & $1370 \pm 238$ & $2389 \pm 618$ & $235 \pm 11$ \\
\hline $\mathrm{J} 10$ & $3500 \pm 338$ & $1320 \pm 213$ & $2180 \pm 519$ & $1228 \pm 5$ \\
\hline $\mathrm{J} 11$ & $5002 \pm 572$ & $1527 \pm 417$ & $3474 \pm 587$ & $303 \pm 19$ \\
\hline \multicolumn{5}{|c|}{ Powders } \\
\hline P1 & $4434 \pm 153$ & $1602 \pm 124$ & $2831 \pm 189$ & $1641 \pm 24$ \\
\hline P2 & $4951 \pm 230$ & $1634 \pm 67$ & $3317 \pm 240$ & $1576 \pm 74$ \\
\hline P3 & $4233 \pm 234$ & $1906 \pm 139$ & $2327 \pm 373$ & $1165 \pm 10$ \\
\hline \multicolumn{5}{|c|}{ Capsules } \\
\hline $\mathrm{C} 1$ & $4511 \pm 184$ & $(2051 \pm 184)^{a}$ & $2459 \pm 31$ & $2468 \pm 102$ \\
\hline $\mathrm{C} 2$ & $5292 \pm 243$ & $(2300 \pm 231)^{\mathrm{a}}$ & $2992 \pm 265$ & $1997 \pm 138$ \\
\hline \multicolumn{5}{|c|}{ Fruit tea } \\
\hline FT1 & $3436 \pm 242$ & $1113 \pm 86$ & $2322 \pm 168$ & $675 \pm 17$ \\
\hline FT2 & $2435 \pm 75$ & $1557 \pm 52$ & $878 \pm 124$ & $459 \pm 34$ \\
\hline FT3 & $1494 \pm 179$ & $574 \pm 55$ & $919 \pm 125$ & $282 \pm 11$ \\
\hline FT4 & $1504 \pm 90$ & $479 \pm 22$ & $1024 \pm 110$ & $353 \pm 16$ \\
\hline \multicolumn{5}{|c|}{ Dried berries } \\
\hline DB1 & $1954 \pm 54$ & $(1086 \pm 74)^{b}$ & $867 \pm 109$ & $(141 \pm 9)^{c}$ \\
\hline DB2 & $2466 \pm 91$ & $(1072 \pm 84)^{\mathrm{b}}$ & $1394 \pm 20$ & $(147 \pm 17)^{c}$ \\
\hline
\end{tabular}

The values are presented as mean \pm standard deviation (S.D.). The same letter in the superscript in the same column indicates no significant differences $(\mathrm{p}>0.05)$. J1-J11=chokeberry juices, P1$\mathrm{P} 3=$ chokeberry powders, $\mathrm{C}=$ chokeberry capsules, $\mathrm{FT}=$ chokeberry fruit tea, DB=chokeberry dried berries. Contents of TPC, TN, TF and TA are expressed as mg per $100 \mathrm{~g}$ of dry matter $(\mathrm{dm})$ in powder, capsule, fruit tea and dried berry samples. Contents of TPC, TN, TF and TA in juice samples are expressed as mg per L. TPC, $\mathrm{TN}$ and TF are expressed as mg of gallic acid equivalent (GAE), while TA are expressed as $\mathrm{mg}$ of cyanidin-3-glucoside equivalents (CGE)

TPC varied between 36.06 and $80.46 \%$. The obtained results suggest that flavonoids were the most abundant phenolics in chokeberry products. Chokeberries are a rich source of anthocyanins, proanthocyanidins and hydroxycinnamic acids (14). Oszmianski and Wojdylo (35) showed that polymeric proanthocyanins are the major class of polyphenolic compounds in chokeberry and represent 66 $\%$ of polyphenols in fruits. Their content ranged between $1578.79 \mathrm{mg}$ per $100 \mathrm{~g}$ of $\mathrm{dm}$ of chokeberry juice up to $8191.58 \mathrm{mg}$ per $100 \mathrm{~g}$ of pomace. In a research of Kapci et al. (47) the content of total flavonoids was higher in chokeberry juices and in dried chokeberries. According to the literature, the main contributor of total flavonoid content is quercetin. Quercetin and several quercetin glycosides (quercetin-3-galactoside, quercetin-3-glucoside and quercetin-3-rutinoside) were also detected in chokeberries but in relatively low mass fractions of about $71 \mathrm{mg}$ per $100 \mathrm{~g}$ of fm (14).

All samples had lower content of TN (808 to $1527 \mathrm{mg}$ of GAE per L and 479 to $2300 \mathrm{mg}$ of GAE per $100 \mathrm{~g}$ of dm) and TA (150 to $1228 \mathrm{mg}$ of CGE per L and 141 to $2468 \mathrm{mg}$ of CGE per $100 \mathrm{~g}$ of $\mathrm{dm}$ ). Chlorogenic and neochlorogenic acids are the major non-flavonoid polyphenolic compounds in chokeberries, and according to Oszmianski and Wojdylo (35) they represent about $7.5 \%$ of chokeberry fruit polyphenols. The hydroxycinnamic acids are represented by significant amounts of chlorogenic (61 to 193 $\mathrm{mg}$ per $100 \mathrm{~g}$ of $\mathrm{fm}$ ) and neochlorogenic acids (85 to 123 $\mathrm{mg}$ per $100 \mathrm{~g}$ of $\mathrm{fm}$ ) (14). Higher contents of TA in chokeberry juice were reported by Jakobek et al. (34) and others $(26,47)$, while Horszwald et al. (40) reported higher content of TA in chokeberry powders. Results of all chokeberry samples were found to be lower, which can be explained by using $\mathrm{pH}$ differential method instead of HPLC method. Anthocyanins represented significant fraction of total phenolics in powder and capsule samples (from 27.53 in P3 to 54.72 \% in C1 sample). Chokeberries contain relatively higher amounts of anthocyanins compared to other fruits including blueberry, blackberry, raspberry, grape and cherry, which are known as rich sources of anthocyanins (14). In research of Jakobek et al. (3) the fraction of anthocyanins in chokeberry was $41 \%$, which was much higher compared to the fraction in red raspberry $(19 \%)$ and strawberry $(23 \%)$. Similar to total phenolic content, Jurgoński et al. (44) reported considerably higher concentration of anthocyanins. Compared to other berries, the aronia anthocyanin profile is very simple, consisting almost exclusively of cyanidin glycosides, namely cyanidin-3-arabinoside, cyanidin-3-galactoside, cyanidin-3-glucoside and cyanidin-3-xyloside. Cyanidin-3-galactoside and cyanidin-3-arabinoside are predominant in the berries with a cumulative content $>90 \%$ (14). Lower levels of total anthocyanins in chokeberry products can be the result of factors such as $\mathrm{pH}$, chemical composition, temperature, light and oxygen. These factors may change easily during processing of fruits into juice and other products. It was reported that anthocyanins are affected at several steps of juice processing, namely pressing, clarification and pasteurisation $(47,48)$.

\section{Total antioxidant capacity and reducing power}

The total antioxidant capacity (TAC) and reducing power (RP) of different chokeberry samples are shown in Table 6. Examined products possess high antioxidant capacity (12.09 to $40.19 \mathrm{mmol}$ of TE per L and 58.49 to 191.31 mmol of TE per $100 \mathrm{~g}$ of $\mathrm{dm}$ ) and reducing power (38.71 to $79.86 \mathrm{mmol}$ of $\mathrm{Fe}^{2+}$ per $\mathrm{L}$ and 13.50 to $68.60 \mathrm{mmol}$ of $\mathrm{Fe}^{2+}$ per $100 \mathrm{~g}$ of $\mathrm{dm}$ ). Highest TAC was reported in dried berries (mean value $187.41 \mathrm{mmol}$ of TE per $100 \mathrm{~g}$ of $\mathrm{dm}$ ), followed by fruit tea (mean value $144.54 \mathrm{mmol}$ of TE per 100 $\mathrm{g}$ of $\mathrm{dm}$ ) and powder (mean value $110.58 \mathrm{mmol}$ of TE per $100 \mathrm{~g}$ of $\mathrm{dm}$ ) samples. The reducing power (FRAP assay) in this study was determined as reduction of $\mathrm{Fe}^{3+}$ to $\mathrm{Fe}^{2+}$. The highest RP was observed in P2 sample $(68.60 \mathrm{mmol}$ of $\mathrm{Fe}^{2+}$ per $100 \mathrm{~g}$ of $\left.\mathrm{dm}\right)$, followed by $\mathrm{C} 1$ sample $(65.82 \mathrm{mmol}$ 
Table 6. Total antioxidant capacity (TAC) and reducing power (RP) of chokeberry products

\begin{tabular}{|c|c|c|}
\hline Sample & TAC & $\mathrm{RP}$ \\
\hline \multicolumn{3}{|c|}{ Juices } \\
\hline $\mathrm{J} 1$ & $33.37 \pm 0.54$ & $76.14 \pm 0.36$ \\
\hline $\mathrm{J} 2$ & $12.09 \pm 0.93$ & $51.50 \pm 0.24$ \\
\hline $\mathrm{J} 2$ & $23.03 \pm 0.53$ & $48.76 \pm 0.48$ \\
\hline $\mathrm{J} 4$ & $19.47 \pm 0.33$ & $72.43 \pm 0.52$ \\
\hline J5 & $18.29 \pm 0.68$ & $48.64 \pm 0.43$ \\
\hline J6 & $20.66 \pm 2.45$ & $79.86 \pm 0.14$ \\
\hline J7 & $16.51 \pm 0.14$ & $38.98 \pm 0.25$ \\
\hline J8 & $34.22 \pm 1.61$ & $71.50 \pm 0.28$ \\
\hline J9 & $26.25 \pm 0.28$ & $38.71 \pm 0.41$ \\
\hline $\mathrm{J} 10$ & $40.19 \pm 2.13$ & $62.92 \pm 0.35$ \\
\hline J11 & $28.12 \pm 0.88$ & $60.13 \pm 0.29$ \\
\hline \multicolumn{3}{|c|}{ Powders } \\
\hline P1 & $95.00 \pm 2.94$ & $60.66 \pm 2.17$ \\
\hline P2 & $105.68 \pm 5.58$ & $68.60 \pm 0.99$ \\
\hline P3 & $131.06 \pm 0.47$ & $47.38 \pm 2.68$ \\
\hline \multicolumn{3}{|c|}{ Capsules } \\
\hline $\mathrm{C} 1$ & $58.49 \pm 7.30$ & $(65.82 \pm 4.20)^{a}$ \\
\hline $\mathrm{C} 2$ & $80.93 \pm 4.56$ & $(60.35 \pm 1.70)^{a}$ \\
\hline \multicolumn{3}{|c|}{ Fruit tea } \\
\hline FT1 & $149.44 \pm 0.89$ & $32.74 \pm 1.66$ \\
\hline FT2 & $111.43 \pm 2.01$ & $43.12 \pm 0.91$ \\
\hline FT3 & $163.33 \pm 4.23$ & $13.50 \pm 0.22$ \\
\hline FT4 & $153.96 \pm 2.99$ & $15.94 \pm 1.32$ \\
\hline \multicolumn{3}{|c|}{ Dried berries } \\
\hline DB1 & $183.52 \pm 4.20$ & $21.51 \pm 2.330$ \\
\hline DB2 & $191.31 \pm 0.38$ & $17.4 \pm 1.0$ \\
\hline
\end{tabular}

The values are presented as mean \pm standard deviation (S.D.). The same letter in the superscript in the same column indicates no significant differences ( $p>0.05)$. TAC is expressed as mmol of Trolox equivalent (TE), while RP is expressed as mmol of $\mathrm{Fe}^{2+}$ equivalents (FE). For chokeberry juices TAC and RP are expressed as mmol of TE per $\mathrm{L}$ and mmol of FE per $\mathrm{L}$, respectively. For powder, capsule, fruit tea and dried berry samples TAC and RP are expressed as mmol of TE per $100 \mathrm{~g}$ of dry matter $(\mathrm{dm})$ and $\mathrm{mmol}$ of FE per $100 \mathrm{~g}$ of $\mathrm{dm}$, respectively

$\mathrm{J} 1-\mathrm{J} 11=$ chokeberry juices, $\mathrm{P} 1-\mathrm{P} 3=$ chokeberry powders, $\mathrm{C}=$ chokeberry capsules, $\mathrm{FT}=$ chokeberry fruit tea, $\mathrm{DB}=$ chokeberry dried berries

of $\mathrm{Fe}^{2+}$ per $100 \mathrm{~g}$ of $\left.\mathrm{dm}\right)$, P1 sample $\left(60.66 \mathrm{mmol}\right.$ of $\mathrm{Fe}^{2+}$ per $100 \mathrm{~g}$ of $\mathrm{dm}$ ) and C2 sample (60.35 mmol of $\mathrm{Fe}^{2+}$ per $100 \mathrm{~g}$ of $\mathrm{dm}$ ). High antioxidant activity of chokeberry fruit and products has been reported in numerous studies $(3,6,14,34,35)$. Walkowaik-Tomczak (48) showed that antioxidant activity of chokeberry juices is under the influence of pasteurisation and storage. Oxygen availability rate during pasteurisation and storage and storage temperature were found to have the biggest effect on the antioxidant activity of chokeberry juices. Reducing power is generally linked to the presence of reducing substances, which have been shown to exert antioxidant activity by breaking the free radical chain by donating a hydrogen atom (49). Antioxidant activity of chokeberry juice concentrate against DPPH radical was stronger than that of black currant, elderberry, red currant, strawberry, red raspberry and cherry concentrate $(3,26)$.

The correlation between the antioxidant activity measured by DPPH and FRAP method and total phenolics is presented in Table 7. Different groups of polyphenolic compounds may contribute differently to total antioxidant activity and, therefore, it is necessary to observe the existence of a correlation between the antioxidant activity and individual groups of polyphenolic compounds. The antiradical activity was mostly affected by the content of

Table 7. Correlation coefficients (R) between phenolics and total antioxidant capacity (TAC) or reducing power (RP) in chokeberry products

\begin{tabular}{|c|c|c|}
\hline Phenolics & TAC & $\mathrm{RP}$ \\
\hline \multicolumn{3}{|c|}{ Juices } \\
\hline TPC & $0.19^{*}$ & $0.29^{* *}$ \\
\hline $\mathrm{TN}$ & 0.47 & $0.37^{*}$ \\
\hline $\mathrm{TF}$ & $0.09^{* *}$ & $0.21^{* *}$ \\
\hline TA & $0.59^{*}$ & $0.47^{* *}$ \\
\hline \multicolumn{3}{|c|}{ Powders } \\
\hline TPC & $-0.45^{*}$ & 0.80 \\
\hline $\mathrm{TN}$ & 0.74 & $-0.72^{*}$ \\
\hline $\mathrm{TF}$ & $-0.60^{* *}$ & 0.86 \\
\hline TA & $-0.94^{* *}$ & 0.84 \\
\hline \multicolumn{3}{|c|}{ Capsules } \\
\hline TPC & 0.85 & $-0.67^{*}$ \\
\hline $\mathrm{TN}$ & 0.52 & $-0.25^{*}$ \\
\hline $\mathrm{TF}$ & 0.84 & $-0.76^{*}$ \\
\hline TA & $-0.86^{*}$ & $0.70^{*}$ \\
\hline \multicolumn{3}{|c|}{ Fruit tea } \\
\hline TPC & $-0.33^{* *}$ & 0.70 \\
\hline $\mathrm{TN}$ & $-0.89^{* *}$ & 0.98 \\
\hline $\mathrm{TF}$ & $0.20^{* *}$ & $0.23^{*}$ \\
\hline TA & $-0.10^{* *}$ & 0.48 \\
\hline \multicolumn{3}{|c|}{ Dried berries } \\
\hline ТPC & $0.76^{* *}$ & $-0.78^{*}$ \\
\hline $\mathrm{TN}$ & $0.10^{*}$ & -0.32 \\
\hline $\mathrm{TF}$ & $0.71^{* *}$ & $-0.68^{*}$ \\
\hline TA & $0.02^{*}$ & 0.09 \\
\hline
\end{tabular}

*,**significant at $\mathrm{p} \leq 0.05$ and $\mathrm{p} \leq 0.001$, respectively Contents of total phenolics (TPC), total nonflavonoids (TN), total flavonoids (TF) and total anthocyanins (TA) are expressed as mg per $100 \mathrm{~g}$ of dry matter $(\mathrm{dm})$ for powder, capsule, fruit tea and dried berry samples. Contents of TPC, TN, TF and TA for juice samples are expressed as mg per L. TPC, TN and TF are expressed as $\mathrm{mg}$ of gallic acid equivalent (GAE), while TA is expressed as mg of cyanidin-3-glucoside equivalents (CGE). TAC and $\mathrm{RP}$ are expressed as mmol per $100 \mathrm{~g}$ of $\mathrm{dm}$ for powder, capsule, fruit tea and dried berry samples. TAC and RP for juice samples are expressed as mmol per L. TAC is expressed as mmol of Trolox equivalent (TE), while RP is expressed as mmol of $\mathrm{Fe}^{2+}$ equivalents (FE) 
phenolic compounds. To see the relationship between the phenolic compounds in chokeberry products and their antiradical activity, TAC and RP values were correlated with the amount of phenolic compounds. This showed that the highest correlation of phenolic compounds and total antioxidant acitivity was between TA and TAC, and between TN and TAC in powder samples, followed by TN and TAC in fruit tea samples. High correlation was also found between TF and RP in powders and between $\mathrm{TN}$ and RP in fruit tea. These results imply that flavonoids and nonflavonoids were the major contributors to the antioxidant capacity of the investigated chokeberry products, especially in the case of powders, fruit tea and capsules. Acording to the data presented by others, TPC of various small fruits correlates better with the antioxidant activity than TA does $(3,9)$. ANOVA showed significant differences between TAC and RP values between groups of chokeberry products and also among individual samples within groups, with the exception of the RP of samples of capsules.

\section{Conclusion}

In this investigation, very high contents of phenolic substances and high values of antioxidant properties were observed in different chokeberry products. The presented data show differences in the quality and phenolic composition of chokeberry juices, powders, capsules, fruit tea and dried berries found on the market. Chokeberry capsules and powders have considerably higher amount of total phenolics and total anthocyanins in comparison with other products. Different levels of antioxidants might be related to the differences in the variety and growing conditions of the fruits. To fully understand the effect of processing, research focused on different processing techniques starting from the same material should be done. Chokeberry products can become a valuable source of nutritionally important substances in human nutrition. Due to the high content of natural antioxidants, their consumption could bring health benefits. Besides studies focusing on different processing techniques, future studies should include additional analyses to obtain a complete evaluation of the quality of chokeberry products and also in vivo and in vitro bioavailability studies. Data from these studies will be helpful to understand the bioaccessibility and bioavailability of nutritive compounds of chokeberry and its products.

\section{Acknowledgements}

This work was supported by the Croatian Ministry of Science, Education and Sports (Project number 0580580696-2808).

\section{References}

1. Nile SH, Park SW. Edible berries: bioactive components and their effect on human health. Nutrition. 2014;30:134-44. http://dx.doi.org/10.1016/j.nut.2013.04.007

2. Seeram NP. Berry fruits for cancer prevention: current status and future prospects. J Agric Food Chem. 2008;56:630-5. http://dx.doi.org/10.1021/jf072504n
3. Jakobek L, Šeruga M, Medvidović-Kosanović M, Novak I. Antioxidant activity and polyphenols of aronia in comparison to other berry species. Agric Conspec Sci. 2007;72:301-6.

4. Persson HA, Jeppsson N, Bartish IV, Nybom H. RAPD analysis of diploid and tetraploid populations of Aronia points to different reproductive strategies within the genus. Hereditas. 2004;141:301-12. http://dx.doi.org/10.1111/j.1601-5223.2004.01772.x

5. Ochmian I, Grajkowski J, Smolik M. Comparison of some morphological features, quality and chemical content of four cultivars of chokeberry fruits (Aronia melanocarpa). Not Bot Horti Agrobo. 2012;40:253-60.

6. Kulling SE, Rawel HM. Chokeberry (Aronia melanocarpa) a review on the characteristic components and potential health effects. Planta Med. 2008;74:1625-34. http://dx.doi.org/10.1055/s-0028-1088306

7. Sueiro L, Yousef GG, Seigler D, de Mejia EG, Grace MH, Lila MA. Chemopreventive potential of flavonoid extracts from plantation-bred and wild Aronia melanocarpa (black chokeberry) fruits. J Food Sci. 2006;71:480-8.

http://dx.doi.org/10.1111/j.1750-3841.2006.00152.x

8. Wawer I. The power of nature - Aronia melanocarpa, 1st ed. London, UK: Nature's Print Ltd.; 2006.

9. Wu X, Gu L, Prior RL, McKay S. Characterization of anthocyanins and proanthocyanidins in some cultivars of Ribes, Aronia, and Sambucus and their antioxidant capacity. J Agric Food Chem. 2004;52:7846-56. http://dx.doi.org/10.1021/jf0486850

10. Slimestad R, Torskangerpoll $\mathrm{K}$, Nateland J, Johannessen T, Giske N. Flavonoids from black chokeberries, Aronia melanocarpa. J Food Comp Anal. 2005;18:61-8. http://dx.doi.org/10.1016/j.jfca.2003.12.003

11. Mattila P, Hellström J, Törrönen R. Phenolic acids in berries, fruits, and beverages. J Agric Food Chem. 2006;54(19):7193-9. http://dx.doi.org/10.1021/jf0615247

12. Koponen JM, Happonen AM, Mattila PH, Torronen AR. Contents of anthocyanins and ellagitannins in selected foods consumed in Finland. J Agric Food Chem. 2007;55(4):1612-9. http://dx.doi.org/10.1021/jf062897a

13. Ovaskainen ML, Torronen R, Koponen JM, Sinkko H, Hellstrom J, Reinivuo H, et al. Dietary intake and major food sources of polyphenols in Finnish adults. J Nutr. 2008;138(3): 562-6.

14. Denev PN, Kratchanov CG, Ciz M, Lojek A, Kratchanova MG. Bioavailability and antioxidant activity of black chokeberry (Aronia melanocarpa) polyphenols: in vitro and in vivo evidences and possible mechanisms of action: a review. Compr Rev Food Sci. 2012;11(5):471-89. http://dx.doi.org/10.1111/j.1541-4337.2012.00198.x

15. Valcheva-Kuzmanova S, Borisova P, Galunska B, Krasnaliev I, Belcheva A. Hepatoprotective effect of the natural fruit juice from Aronia melanocarpa on carbon tetrachloride-induced acute liver damage in rats. Exp Toxicol Pathol. 2004; 56:195-201.

http://dx.doi.org/10.1016/j.etp.2004.04.012

16. Valcheva-Kuzmanova S, Kuzmanov K, Mihova V, Krasnaliev I, Borisova P, Belcheva A. Antihyperlipidemic effect of Aronia melanocarpa fruit juice in rats fed a high cholesterol diet. Plant Food Hum Nutr. 2007a;62:19-24. http://dx.doi.org/10.1007/s11130-006-0036-2

17. Valcheva-Kuzmanova S, Kuzmanov K, Tanchevam S, Belchevam S. Hypoglycemic and hypolipidemic effects of Aronia melanocarpa fruit juice in streptozotocin-induced diabetic rats. Method Find Exp Clin Pharmacol. 2007b;29(2):1-5. http://dx.doi.org/10.1358/mf.2007.29.2.1075349

18. Ryszawa N, Kawczynska-Drozdz A, Pryjma J, Czesnikiewicz-Guzik M, Adamek-Guzik T, Naruszewicz M, et al. 
Effects of novel plant antioxidants on platelet superoxide production and aggregation in arteriosclerosis. J Physiol Pharmacol. 2006;57:611-26.

19. Ohgami K, Ilieva I, Shiratori K, Koyama Y, Jin XH, Yoshida $\mathrm{K}$, et al. Effects of novel plant antioxidants on platelet superoxide production and aggregation in atherosclerosis. Invest Ophth Vis Sci. 2005;46:275-81.

20. Naruszewicz M, Łaniewska I, Millo B, Dłużniewski M. Combination therapy of statin with flavonoids rich extract from chokeberry fruits enhanced reduction in cardiovascular risk markers in patients after myocardial infraction (MI). Atherosclerosis. 2007;194:179-84. http://dx.doi.org/10.1016/j.atherosclerosis.2006.12.032

21. Bell DR, Gochenaur K. Direct vasoactive and vasoprotective properties of anthocyanin-rich extracts. J Appl Physiol. 2006; 100:1164-70. http://dx.doi.org/10.1152/japplphysiol.00626.2005

22. Chrubasik C, Li G, Chrubasik S. The clinical effectiveness of chokeberry: a systematic review. Phytother Res. 2010;24: 1107-14. http://dx.doi.org/10.1002/ptr.3226

23. Official Methods of Analysis. 18th ed. Washington, D.C., USA: Association of Official Analytical Chemists (AOAC); 2000.

24. McGuire RG. Reporting of objective colour measurements. Hort Sci. 1992;27(12):1254-5.

25. Voss DH. Relating colourimeter measurement of plant colour to the royal horticultural society colour chart. Hort Sci. 1992;27(12):1256-60

26. Benvenuti S, Pellati F, Melegari M, Bertelli D. Polyphenols, anthocyanins, ascorbic acid, and radical scavenging activity of rubus, ribes, and aronia. J Food Sci. 2004;69:164-9. http://dx.doi.org/10.1111/j.1365-2621.2004.tb13352.x

27. Waterhouse AL: Determination of total phenolics. In: Wrolstad $\mathrm{RE}$, editor. Current protocols in food analytical chemistry. New York, NY, USA: John Wiley and Sons Inc.; 2002. pp. I 1.1.1.-1.1.8

28. Ough CS, Amerine MA. Methods for analysis of musts and wines. Hoboken, NY, USA: John Wiley and Sons Inc.; 1988.

29. Giusti MM, Wrolstad RE: Characterization and measurement of anthocyanins by UV-visible spectroscopy. In: Wrolstad RE, editor. Current protocols in food analytical chemistry. New York, NY, USA: John Wiley and Sons Inc.; 2002. pp. F 1.2.1.-1.2.13

30. Brand-Williams W, Cuvelier ME, Berset C. Use of a free radical method to evaluate antioxidant activity. LWT-Food Sci Technol. 1995;28:25-30. http://dx.doi.org/10.1016/S0023-6438(95)80008-5

31. Benzie IFF, Strain JJ. The ferric reducing ability of plasma (FRAP) as a measure of 'antioxidant power': The FRAP assay. Anal Biochem. 1996;239:70-6. http://dx.doi.org/10.1006/abio.1996.0292

32. Zheng W, Wang SY. Oxygen radical absorbing capacity of phenolics in blueberries, cranberries, chokeberries, and lingonberries. J Agric Food Chem. 2003;51:502-9. http://dx.doi.org/10.1021/jf020728u

33. Rop O, Mlcek J, Jurikova T, Valsikova M, Sochor J, Reznicek V, Kramarova D. Phenolic content, antioxidant capacity, radical, oxygen species scavenging and lipid peroxidation inhibiting activities of extracts of five black chokeberry (Aronia melanocarpa (Michx.) Elliot) cultivars. J Med Plant Res. 2010;4(22):2431-7. http://dx.doi.org/10.5897/JMPR10.576

34. Jakobek L, Drenjančević M, Jukić V, Šeruga M. Phenolic acids, flavonols, anthocyanins and antiradical activity of 'Nero', 'Viking', 'Galicianka' and wild chokeberries. Sci Hortic. 2012;
147:56-63.

http://dx.doi.org/10.1016/j.scienta.2012.09.006

35. Oszmianski J, Wojdylo A. Aronia melanocarpa phenolics and their antioxidant activity. Eur Food Res Technol. 2005;221: 809-13. http://dx.doi.org/10.1007/s00217-005-0002-5

36. Mayer-Miebach E, Adamiuk M, Behsnilian D. Stability of chokeberry bioactive polyphenols during juice processing and stabilization of a polyphenol-rich material from the by-product. Agriculture. 2012;2(3):244-58. http://dx.doi.org/10.3390/agriculture2030244

37. Sójka M, Kołodziejczyk K, Milala J. Polyphenolic and basic chemical composition of black chokeberry industrial by-products. Ind Crop Prod. 2013;51:77-86. http://dx.doi.org/10.1016/j.indcrop.2013.08.051

38. Potter N. Food science. 3rd ed. Westport, CT, USA: AVI Publishing Company Inc; 1978.

39. Rebeck HM. Processing of citrus juices. In: Ashurst PR, editor. Production and packaging of non-carbonated fruit juices and fruit beverages. 2nd ed. London, UK: Blackie Academic and Professional; 1995. pp. 221-52.

40. Horszwald A, Julien H, Andlauer W. Characterization of Aronia powders obtained by different drying process. Food Chem. 2013;141:2858-63. http://dx.doi.org/10.1016/j.foodchem.2013.05.103

41. Ferrer A, Remón S, Negueruela AI, Oria R. Changes during the ripening of the very late season Spanish peach cultivar Calanda: feasibility of using CIELAB coordinates as maturity indices. Sci Hortic. 2005;105:435-46. http://dx.doi.org/10.1016/j.scienta.2005.02.002

42. Wrolstad RE, Durst RW, Lee L. Tracking color and pigment changes in anthocyanin products. Trends Food Sci Technol. 2005;16:423-8. http://dx.doi.org/10.1016/j.tifs.2005.03.019

43. Gonçalves B, Silva AP, Moutinho-Pereira J, Bacelar E, Rosa E, Meyer AS. Effect of ripeness and postharvest storage on the evolution of colour and anthocyanins in cherries (Prunus avium L.). Food Chem. 2007;103:976-84. http://dx.doi.org/10.1016/j.foodchem.2006.08.039

44. Jurgoński A, Juśkiewicz J, Zduńczyk Z. Ingestion of black chokeberry fruit extract leads to intestinal and systemic changes in a rat model of prediabetes and hyperlipidemia. Plant Foods Hum Nutr. 2008;63:176-82. http://dx.doi.org/10.1007/s11130-008-0087-7

45. Chang CH, Lin HY, Chang YC, Liu YC. Comparisons of the antioxidant properties of fresh, freeze-dried and hot-airdried tomatoes. J Food Eng. 2006;77:478-85. http://dx.doi.org/10.1016/j.jfoodeng.2005.06.061

46. Shin Y, Ryu J, Liu RH, Nock JF, Watkins CB. Harvest maturity, storage temperature and relative humidity affect fruit quality, antioxidant contents and activity, and inhibition of cell proliferation of strawberry fruit. Postharvest Biol Technol. 2008;49:201-9. http://dx.doi.org/10.1016/j.postharvbio.2008.02.008

47. Kapci B, Neradova E, Čížková H, Voldřich M, Rajchl A, Capanoglu E. Investigation the antioxidant potential of chokeberry (Aronia melanocarpa) products. J Food Nutr Res. 2013; 52(4):219-29.

48. Walkowiak-Tomczak D. Changes in antioxidant activity of black chokeberry juice concentrate solutions during storage. Acta Sci Pol Technol Aliment. 2007;6(2):49-55.

49. Koca I, Karadeniz B. Antioxidant properties of blackberry and blueberry fruits grown in the Black Sea Region of Turkey. Sci Hortic. 2009;121:447-50. http://dx.doi.org/10.1016/j.scienta.2009.03.015 